\title{
O debate sobre direitos linguísticos e o lugar do linguista na luta dos sujeitos falantes de línguas minorizadas: quem são os protagonistas?
}

\section{The debate on language rights and the linguist's place in the struggle of the speakers of minority languages: who are the protagonists?}

Julia Izabelle da Silva

Universidade Federal de Santa Catarina

Florianópolis, Santa Catarina / Brasil

RESUMO: Neste artigo, buscamos promover o debate teórico acerca dos direitos linguísticos e, ao mesmo tempo, problematizar o lugar do linguista nos processos de luta protagonizados pelos sujeitos falantes de línguas historicamente minorizadas. Para isso, apresentamos os argumentos dos autores que defendem os direitos linguísticos de minorias linguísticas e seus pressupostos teóricos, assim como as recentes críticas que têm sido feitas a tal paradigma, de modo a incitar uma reflexão sobre nossas práticas e posicionamentos enquanto teóricos da linguagem que falam de um lugar privilegiado. Concluímos que, no que concerne aos direitos linguísticos e às políticas linguísticas neles implicadas, os próprios sujeitos falantes das línguas minorizadas é que devem protagonizar tais debates, cabendo a nós, intelectuais acadêmicos, o papel de garantir espaços e condições para que a voz desses sujeitos seja ouvida.

PALAVRAS-CHAVE: direitos linguísticos; línguas minorizadas; protagonismo.

\begin{abstract}
In this article we aimed to promote the theoretical debate on language rights and, at the same time, to question the place of the linguist in the processes of struggle carried out by the subjects who historically speaks minority languages. For this, we present the arguments from authors who defend the language rights of linguistic minorities and their theoretical assumptions, as well as recent criticisms that have been made to such a paradigm, in order to incite a reflection on our practices and positions as language theorists who speak from a privileged place. We concluded that, with regard to language rights and the language policies implied, the very subjects who speak the minority languages should be the protagonists of such debates, and it is up to us, academic intellectuals, the role of ensuring spaces and conditions for the voice of these subjects to be heard.
\end{abstract}

KEYWORDS: language rights; language minorities; protagonism.

*juliaisilva27@gmail.com 


\section{Introdução}

Nas últimas décadas, o tema dos direitos linguísticos ganhou relevância tanto no cenário internacional como em contextos nacionais e regionais. Desde a Declaração Universal dos Direitos Humanos, de 1948, o direito ao uso individual e coletivo das línguas tem constado em diversos pactos, declarações internacionais e constituições. Em1996, uma ampla mobilização de organizações não governamentais, movimentos sociais e acadêmicos resultou na Declaração Universal dos Direitos Linguísticos, considerada atualmente o principal instrumento político contra a discriminação linguística (OLIVEIRA, 2003). No Brasil, a temática ganhou fôlego com a mobilização de diferentes comunidades linguísticas, as quais protagonizaram a luta pelo reconhecimento de suas línguas enquanto a comunidade surda se mobilizou para garantir o reconhecimento jurídico da Língua Brasileira de Sinais (Libras) como segunda língua oficial do país, quinze comunidades indígenas e de descendentes de imigrantes se organizaram politicamente para que suas línguas também fossem reconhecidas como cooficiais nos municípios onde se fazem presentes (MORELLO, 2015). Assim, a luta pela garantia de direitos linguísticos no Brasil tem constituído um movimento político cujos protagonistas são os próprios sujeitos falantes das línguas historicamente discriminadas.

Como paradigma acadêmico, os direitos linguísticos têm sido alvo de debates entre teóricos que sustentam posicionamentos distintos. Há quem adote uma postura de defesa e militância pelos direitos linguísticos a partir de pressupostos teóricos já tradicionais na literatura sobre o tema. Essa posição é verificada em diferentes círculos acadêmicos, os quais, preocupados seja com o desaparecimento das línguas ameaçadas de extinção (KRAUSS, 1992; NETTLE; ROMAINE, 2000), seja com a garantia de direitos humanos às minorias linguísticas (MAY, 2005; SKUTNABB-KANGAS; PHILLIPSON, 2008; VARENNES, 2015), alertam para a urgência de políticas de proteção e suporte às línguas minorizadas. Recentemente, no entanto, muitos teóricos têm sustentado uma visão crítica dos princípios que orientam os direitos linguísticos. Nos últimos anos, a Linguística Aplicada Crítica, sobretudo a partir dos trabalhos de Edwards (2006), Makoni e Pennycook (2007), Makoni (2012), entre outros, tem problematizado o discurso de defesa e promoção das línguas minorizadas a partir de uma revisão tanto das categorias que embasam esse discurso como da adequação dos direitos linguísticos a contextos locais. 
Contudo, mesmo em face do debate teórico sobre o tema, quando falamos de mobilização política pelo reconhecimento de uma língua historicamente minorizada, como foi o caso do movimento surdo pela oficialização da Libras no Brasil, notamos que, mais do que um paradigma acadêmico, os direitos linguísticos funcionam como um instrumento de luta e resistência de movimentos que, muitas vezes, pouco ou nada se aproximam das discussões teóricas. Tais movimentos são, em geral, constituídos por sujeitos que diariamente vivenciam a experiência discriminatória de não serem falantes nativos da língua hegemônica de onde vivem. Na condição de subalternos ${ }^{1}$, esses sujeitos dificilmente ocupam espaços hegemônicos, como o ambiente acadêmico, o que, para usar a expressão de Spivak (2014), impede que eles possam falar e ser ouvidos. Diante disso, somos levados a questionar: qual o papel que nós, teóricos da linguagem, ocupantes de espaços institucionais hegemônicos como a universidade, temos nos movimentos pelos direitos linguísticos? Qual seria o nosso lugar de fala e a nossa tarefa em uma luta cujo protagonismo não é nosso? Afinal, quais vozes e práticas estamos priorizando nesse debate?

Neste artigo, buscaremos trazer a voz do intelectual teórico dos direitos linguísticos, para, em seguida, questionar a legitimidade dessa voz nos processos de luta dos sujeitos falantes de línguas minorizadas. Em primeiro lugar, devemos ressaltar que o tema dos direitos linguísticos não se encerra na defesa das línguas minorizadas, pois o acesso ao ensino e à aprendizagem da língua oficial do Estado, assim como de línguas estrangeiras, constitui direito linguístico fundamental, que deve ser garantido pelos Estados. No entanto, para o objetivo deste artigo, trataremos exclusivamente dos direitos linguísticos voltados à defesa de línguas minorizadas. Tal escolha se justifica pelo fato de que a promoção dessas línguas nos espaços públicos é algo que tem gerado controvérsias e debates tanto entre acadêmicos quanto entre sociedade civil e Estado.

\footnotetext{
${ }^{1} \mathrm{O}$ termo subalterno, referenciado no texto de Spivak (2014), é utilizado aqui no sentido gramsciano de subjetivação política de grupos ou classes em contextos de hegemonia. A nosso ver, os falantes de línguas minorizadas se inserem na experiência da subalternidade na medida em que suas práticas linguísticas sofrem as iniciativas de grupos dominantes, sendo, portanto, submetidas às políticas linguísticas hegemônicas. Ao mesmo tempo, o sujeito subalterno agencia tais práticas linguísticas como formas de resistência, em um processo de contra-hegemonia.
} 
Assim, na primeira parte do texto, nos concentraremos em alguns dos argumentos que especialistas como Varennes (2015) e May (2005) apresentam em defesa dos direitos linguísticos das minorias linguísticas. $\mathrm{Na}$ segunda parte, focaremos as recentes críticas que o tema recebe, trazendo, para isso, as análises de autores como Edwards (2006), Makoni e Pennycook (2007) e Makoni (2012). Por fim, na última parte do texto, a partir das considerações de Spivak (2014) e de Belausteguigoitia (2001), buscaremos problematizar o modo como o intelectual teórico da linguagem pretende representar os interesses dos sujeitos falantes de línguas minorizadas. Consideramos que, ao tentar mediar e protagonizar o debate sobre direitos linguísticos sem reconhecer a maneira como os sujeitos falantes vivenciam suas práticas linguísticas, o linguista silencia a voz do subalterno e produz uma forma de violência epistêmica.

\section{Direitos linguísticos: uma questão de justiça social e de reparação histórica}

A literatura especializada já demonstrou que os séculos XIX e XX foram marcados por uma série de políticas de repressão à diversidade linguística (cf. ANDERSON, 2015; HOBSBAWN, 2013; OLIVEIRA, 2002; VARENNES, 2015). Durante o processo de modernização e de centralização dos Estados nacionais, a ideologia predominante era a de que a homogeneidade linguística garantiria a unidade nacional, sendo, para isso, necessário escolher uma única língua oficial para a nação. Assim, à medida que a heterogeneidade de línguas e variedades era considerada um "entrave" para o desenvolvimento nacional, os cidadãos cujas línguas não correspondiam à oficial dos Estados em que se encontravam sofreram toda sorte de discriminação e exclusão social. De acordo com o especialista em Direitos Humanos de Minorias e direitos linguísticos, Fernand de Varennes (2015), ao excluir o uso das demais línguas da esfera pública, as autoridades estatais excluíam seus falantes do exercício da cidadania, pois dificultavam o acesso às oportunidades educacionais e de emprego, por exemplo. $\mathrm{Na}$ perspectiva defendida por esse autor, a exclusividade da língua dominante como oficial do Estado ainda hoje coloca os falantes dessa língua em vantagem, tanto no acesso a serviços e benefícios estatais quanto no controle de áreas administrativas, políticas, educacionais e econômicas (VARENNES, 2015). Ao mesmo tempo, aqueles que possuem pouco ou nenhum domínio da língua oficial do Estado têm o uso de sua língua materna limitado a 
domínios específicos, geralmente privados e domésticos, de menor status social, o que, por consequência, coloca esses grupos em desvantagem social, política e econômica. Nesse sentido, Piller (2016) tece uma discussão sobre o modo como as barreiras linguísticas enfrentadas por falantes de línguas minorizadas podem estar relacionadas a problemas de desigualdade e injustiça social. Conforme explica a autora,

estamos diante de uma celebração da diversidade lingüística no resumo que choca com a existência patente de problemas sociais associados à diversidade linguística: jovens minoritários em desvantagem no mercado de trabalho australiano, escolas com populações diversas com desempenho inferior nos EUA ou barreiras à saúde e serviços jurídicos enfrentados pelos migrantes no Reino Unido (PILLER, 2016, p. 3, tradução nossa) $)^{2}$.

Para Piller (2016, p. 5), o debate contemporâneo sobre justiça social está focado principalmente nas desvantagens e discriminações baseadas em questões de gênero, raça, religião, orientação sexual, etnicidade etc., de forma que "é extremamente raro que a língua seja considerada um fator pelo qual indivíduos, comunidades ou nações podem ser excluídos”. Nesse sentido, a autora defende que é preciso entender melhor a relação entre a exclusão de línguas minorizadas e a desigualdade econômica, a dificuldade de acesso a serviços públicos, como saúde, justiça e educação, assim como a falta de participação política e de exercício da cidadania em geral. Nas palavras da autora, "se nós não formos capazes de, ao menos, reconhecer as desvantagens e discriminações com base na língua, nós não seremos capazes de trabalhar para uma mudança positiva” (PILLER, 2016, p. 5).

Nesse sentido, Varennes (2015) advoga por direitos linguísticos que garantam o uso das línguas minorizadas nas instituições públicas, a fim de assegurar o acesso desses grupos a serviços públicos básicos e a maiores oportunidades de emprego. Segundo o autor, os direitos linguísticos constituem um instrumento que pode permitir maior participação desses indivíduos na vida pública e, portanto, no exercício da cidadania. Assim, a defesa do direito de esses grupos usarem suas línguas nas instituições públicas representa uma forma de inclusão e justiça social. Nas palavras de Varennes,

\footnotetext{
2 "we are faced with a celebration of linguistic diversity in the abstract that clashes with the patent existence of social problems associated with linguistic diversity: minority youths being disadvantaged in the Australian job market, schools with diverse populations underperforming in the USA, or barriers to health and legal service faced by migrants in the UK".
} 
uma abordagem generosa e prática para o uso de línguas minoritárias por parte dos Estados ajuda as minorias a alcançar acesso igual a serviços e oportunidades. Ao utilizar as suas línguas, as autoridades contribuem de forma mais eficaz para as minorias, na medida em que estão mais bem informadas, participam mais eficazmente na vida pública e têm um melhor acesso aos serviços e às oportunidades. A utilização da língua das minorias contribui assim para a sua inclusão em todas as facetas da sociedade e promove a coexistência pacífica. Usar somente uma língua oficial pode resultar em sua exclusão desproporcional - e potencialmente servir para alienar, criar desvantagem e antagonizar parte da própria população do estado (VARENNES, 2015, p. 46 tradução nossa) ${ }^{3}$.

No entanto, embora os direitos linguísticos constituam um tema já consolidado na legislação internacional e em algumas legislações nacionais, a defesa das línguas minoritárias no interior dos Estados nacionais é um assunto que encontra muita resistência. Para autores como Hamel (1995), essa resistência está associada à ideologia da nação homogênea e monolíngue que consolidou os Estados nacionais nos séculos XIX e XX e que ainda hoje persiste entre a classe hegemônica. $\mathrm{Na}$ análise do autor, os direitos linguísticos são confrontados com a crença de que garantir direitos coletivos a grupos etnicamente distintos poderia colocar em risco a unidade e a soberania da nação, constituindo, assim, uma verdadeiraameaça à segurança nacional (HAMEL, 1995)). Nesse sentido, há uma série de argumentos hegemônicos que têm sido utilizados para tentar "derrubar" os movimentos pelo reconhecimento das línguas minoritárias.

Segundo May (2005), um desses argumentos é o de que os direitos linguísticos sejam uma tentativa de volta ao passado, uma utopia que não pode ser alcançada. Tal argumento se pauta no princípio de que as mudanças linguísticas são irreversíveis e incontroláveis e que, portanto, não há o que fazer para reverter esse processo. No entanto, segundo o autor, a ideia de que o avanço das línguas majoritárias seja algo inevitável constitui um presentismo que desconsidera os fatores históricos e políticos que levaram à situação atual:

\footnotetext{
3 “a generous yet practical approach towards the use of minority languages by states helps minorities achieve equal access to services and opportunities. By using their languages, authorities contribute more effectively to minorities as far as being better informed, participating more effectively in public life, and having better access to services and opportunities. Using the language of minorities thus contributes to their inclusion in all facets of society and promotes peaceful coexistence. To only use one official language can result in their disproportionate exclusion - and potentially serve to alienate, disadvantage, and antagonize part of a state's own population".
} 
o mesmo pode ser dito para a abordagem ahistórica e apolítica da linguagem que muitas vezes sustenta essa crítica particular dos direitos linguísticos. Isto é mais evidente na legitimidade quase inquestionável atribuída às línguas majoritárias, particularmente às línguas nacionais, nessas discussões [...] e na inquestionável aceitação de sua posição social e política dominante e função na ascendência normativa dentro dos Estados-nação modernos. Adotar uma abordagem presentista implica inevitavelmente ignorar ou, na melhor das hipóteses, subestimar os processos sócio-históricos e sociopolíticos específicos pelos quais essas línguas majoritárias passaram a ser criadas e aceitas como dominantes e legítimas (MAY, 2015, p. 322, tradução nossa) ${ }^{4}$.

Ao aceitar a inevitabilidade de as línguas majoritárias - particularmente as nacionais - serem as únicas passíveis (e desejáveis) de assumirem funções e posições normativas em dada estrutura social, os discursos hegemônicos acabam por legitimar não só a superioridade inquestionável das línguas dominantes e todo o valor simbólico de mais adequadas à modernização que elas já carregam, como também os processos sócio-históricos e sociopolíticos de dominação colonial e pós-colonial, os quais, como sabemos, tiveram na língua e em sua discursivização um dos principais meios de legitimação. Tais discursos se revelam problemáticos, na medida em que o resultado de um processo histórico é tomado como algo natural e, portanto, inevitável e irreversível na contemporaneidade - não há espaço para pensar que outras línguas possam ocupar um status de legitimidade social, já que este é e sempre será o lugar do inglês, do espanhol, do francês... Portanto, mesmo que se reconheça a brutalidade das práticas linguísticas do passado, ainda haverá o problema do fait accompli- "nós podemos bem nos arrepender do passado, mas não há nada que possamos fazer sobre isso agora, portanto isso não deve, nem pode, influenciar nosso presente. O que está feito, está feito" (MAY, 2005, p. 325). Para May, o primeiro problema de tal perspectiva é que ela encerra as línguas em funções mutuamente excludentes - enquanto

\footnotetext{
4 "much the same can be said for the ahistorical, apolitical approach to language that too often underpins this particular critique of language rights. This is most evident in the almost unquestioned legitimacy ascribed to majority languages particularly national languages in such discussions [...], and the similarly unquestioned acceptance of their dominant social and political position and function their normative ascendancy within modern nation-states. Adopting a presentist approach inevitably entails ignoring, or at best underemphasising, the specific sociohistorical and socio-political processes by which these majority languages have come to be created, and accepted as dominant and legitimate, in the first place".
} 
a língua dominante é a única autorizada a assumir um papel instrumental, a língua dominada é associada somente a valores sentimentais. Assim, a língua minoritária pode ter importância para a identidade, mas não um valor instrumental. Com isso, supõe-se, ainda que de modo implícito, que somente as línguas majoritárias possam ser veículos de modernidade, ciência, arte etc. Segundo May, ver as coisas dessa forma é desconsiderar os processos políticos e sociais que levaram essas línguas a tais funções. Se repensarmos o modo como os valores dessas línguas foram, ao longo da história, distribuídos na balança social, veremos que a instrumentalidade das línguas minoritárias não precisa ser limitada para sempre.

Além disso, May considera que, embora a promoção de uma língua minoritária não seja, por si só, suficiente para transformar a sociedade ou mesmo emancipar um grupo minoritário específico, ela somente tem a contribuir com tal processo. Afinal, quando os defensores dos direitos linguísticos advogam pelo uso e pela aprendizagem de determinada língua, raramente questionam a importância da língua dominante. É por isso que em grande parte dos casos de promoção do status linguístico de uma língua minoritária se fala em cooficialização e não em substituição da língua majoritária, por exemplo. De acordo com o autor, o que se propõe, portanto, é uma relação de complementariedade. A promoção de uma língua não necessariamente impede a promoção de outra.

Assim, advogar por bilinguismo ou multilinguismo público é pedir para que os falantes monolíngues se acomodem à presença de outra língua no contexto estatal e reconheçam seu status não só de valor sentimental, mas de instrumentalidade para a vida moderna. Para nós, falantes de línguas majoritárias, trata-se simplesmente do que o autor chama de "mútua acomodação". Para os falantes de outras línguas, trata-se da possibilidade histórica de fazer uso de sua língua no contexto público, no ambiente científico, tecnológico, político etc.; de poder afirmar-se identitariamente de maneira positiva; diz respeito ao valor simbólico de ver, finalmente, reconhecido algo que por séculos foi tomado como "errado", "impuro", "diabólico" (cf. BESSA FREIRE, 1983, p. 39). Enfim, se trata de reparar uma dívida histórica e de garantir que todos os cidadãos tenham os mesmos instrumentos de acesso à cidadania (VARENNES, 2015).

May (2005) lembra, ainda, que o problema de se tomar a homogeneidade linguística como uma realidade contra a qual nada se pode fazer é que acabamos fechando os olhos para as possibilidades de 
repensar nosso modelo de Estado a partir de formas alternativas mais plurais. Assim, o autor afirma que há muitos exemplos contemporâneos de países onde as concepções de Estado-nação são pautadas por princípios de pluralidade linguística e cultural. O Quebéc, a Bélgica, a Espanha, a Suécia e, mais recentemente, a Bolívia, o Peru e o Equador são algumas das nações autoproclamadas plurilíngues.

A promoção das línguas indígenas a cooficiais em alguns países latinoamericanos é um exemplo de como os direitos linguísticos podem compor, junto com outros direitos coletivos, como o direito ao território, à educação específica e à autodeterminação, aquilo que Santos (2010) chamou de "a nova linguagem emancipatória dos povos subalternos". Nessa perspectiva, o discurso pelos direitos linguísticos, ao invés de representar uma resistência à mudança e à modernização, representaria uma entre várias estratégias de manipulação e reapropriação dos direitos modernos que caracterizam as práticas políticas contemporâneas dos grupos minoritários.

No entanto, análises críticas mais recentes têm desconfiado da afirmação de pluralidade linguística e cultural proferida pelos Estados nacionais. Tais análises consideram que, ao invés de promoverem a diversidade e heterogeneidade linguística, as políticas de promoção das línguas minoritárias acabam construindo novas hierarquias linguísticas. Isto é, ao favorecerem determinada língua, os direitos linguísticos desqualificam as demais variedades e práticas hibridizantes, que também compõem a paisagem linguística contemporânea. $\mathrm{Na}$ próxima seção, apresentamos algumas das principais críticas que, recentemente, têm sido feitas ao paradigma dos direitos linguísticos e, mais especificamente, ao discurso de defesa e proteção das línguas minoritárias.

\section{Críticas aos direitos linguísticos: línguas ameaçadas e o problema da objetificação}

Nos últimos anos, o paradigma dos direitos linguísticos vem recebendo críticas que nada têm a ver com os discursos hegemônicos nacionalistas e homogeneizantes discutidos na seção anterior. Tais críticas não pretendem "desmantelar" os direitos das minorias linguísticas, advogando, assim, o monolinguismo e a unidade nacional; muito pelo contrário, invocam questões e reflexões necessárias para repensar e aprofundar a promoção da heterogeneidade linguística e suas hibridizações no mundo pós-moderno. Assim, uma das principais críticas diz respeito ao já 
tradicional discurso das línguas ameaçadas de extinção. Sabemos que a ideia de que é preciso resgatar, revitalizar e proteger as línguas faladas por grupos minorizados para evitar que desapareçam constitui hoje um vasto campo de atuação de linguistas engajados na preservação da diversidade linguística (cf. FISHMAN, 1991; KRAUSS, 1992; NETTLE; ROMAINE, 2000). No entanto, esse movimento de salvar línguas como se salvam espécies da extinção, sob a alegação de que isso representaria uma perda incalculável para a humanidade (KRAUSS, 1992), é alvo de análises mais críticas ${ }^{5}$.

Para John Edwards (2006), é no mínimo inocente pensar que a mudança linguística, intrínseca a qualquer forma de construção social, possa ser controlada através de medidas de intervenção. Na perspectiva do autor, intervir a favor de uma língua minoritária nem sempre é algo que condiz com o desejo ou com as necessidades da comunidade, já que o contato com outras sociedades implica uma dinâmica de mudança constante, de apropriação e reapropriação de significados sociais, políticos, econômicos, culturais e - por que não? - linguísticos. Além disso, Edwards (2006, p. 103) questiona o que poderia, afinal, ser considerada uma língua revitalizada: "Poderia uma língua preservada na forma escrita, mas falada por poucos (ou ninguém), em bases regulares, ser considerada 'mantida'?".

No entanto, se torna cada vez mais proeminente o discurso ecológico segundo o qual é preciso que os linguistas se comprometam com o resgate dessas línguas; pois, caso contrário, as próximas gerações veriam uma "destruição catastrófica" das línguas do mundo (KRAUSS, 1992). Para Edwards, o problema desse discurso é que uma intervenção que alguns podem ver como absolutamente necessária pode ser considerada por outros como inapropriada e até perigosa. Afinal, argumenta o autor, muitas vezes o esforço de linguistas em manter uma língua não é suficientemente necessário ou importante, se comparado à realidade das pressões políticas e econômicas que os grupos falantes dessas línguas vivenciam e que os obriga a aprender a língua dominante. Desse ponto de vista, o linguista engajado na revitalização linguística não está comprometido com a vida das pessoas que falam o idioma em perigo, com transformação social, mas tão somente com a língua em si, tomada como objeto, artefato a ser resguardado e conservado, peça de museu. Como Edwards avalia,

\footnotetext{
${ }^{5}$ Sobre os discursos que entendem a propagação do inglês e a assimilação linguística como catástrofes a serem combatidas, confira Jacquemet (2005) e Sylvia (2016b).
} 
a ecologia de línguas é agora uma indústria em vertiginoso crescimento, mas é difícil ver que ela tem feito a alguém algum bem - exceto, claro, para aqueles acadêmicos que encontraram ampla oportunidade para publicarem argumentos do lado dos anjos, e para promoverem o debate, se apenas entre eles mesmos (EDWARDS, 2006, p. 101, tradução nossa) ${ }^{6}$.

A esse respeito, Oliveira (1999), ao discutir a questão da assessoria de linguistas em projetos de educação escolar indígena no Brasil, chama a atenção para uma crença generalizada entre as áreas da Linguística dedicadas a esse tema de que o papel do linguista seja descrever e documentar as línguas indígenas e, em alguns casos, instrumentalizá-las com dicionários, gramáticas e ortografias. A ideia de que cabe ao linguista a nobre tarefa de registrar a gramática dessas línguas nos leva novamente à ideia de maior comprometimento com as línguas-objeto do que com os sujeitos que as falam. Como observa Oliveira (1999, p. 27), "muitas das justificativas dadas por esses profissionais para o trabalho com as línguas indígenas têm compromisso muito maior com a tradição da própria disciplina do que com as necessidades dos professores indígenas e dos projetos que os contratam".

Assim, quando falamos em direitos linguísticos temos margem para duas interpretações possíveis: trata-se do direito da lingua ou do direito dos falantes que a utilizam? Esse é um ponto importante a ser refletido por aqueles que se detêm no tema. Uma visão objetificante da língua levaria à primeira interpretação, de modo que o que estaria em jogo seria única e exclusivamente a preservação de sistemas gramaticais. Nessa perspectiva, o que acontece com a vida das pessoas que falam essa língua não é da alçada do linguista. O que se defende, portanto, é o direito de que as línguas sejam preservadas e armazenadas em bancos de dados para futuras análises científicas. Por outro lado, uma visão que defenda o direito dos falantes deve estar preocupada com os interesses dos sujeitos, sejam esses interesses a vontade de ter um dicionário em língua materna ou de ter acesso a uma língua majoritária - o inglês, por exemplo.

Nesse sentido, Severo (2014, p. 9) critica o modo como os discursos científicos, sob a justificativa de uma "suposta ameaça de desaparecimento",

\footnotetext{
6 "the ecology of language is now very much a growth industry, but it is hard to see that it has done anyone any good - except, of course, for those scholars who have found ample opportunity for publishing arguments on the side of the angels, and for fostering debate, if only amongst themselves".
} 
objetificam as línguas como artefatos a serem geridos e protegidos. De acordo com a autora, a objetificação das línguas constitui, em realidade, um ato político, na medida em que, ao separá-las dos sujeitos e de suas histórias, atribui a elas uma neutralidade e autonomia que não existem. Segundo a autora, as línguas não podem ser dissociadas das práticas sociais e das condições históricas em que são usadas. Portanto, ao conceber as línguas como entidades abstratas, passíveis de registro ou mesmo revitalização, o discurso científico nega o caráter inerentemente dinâmico, dialógico e político delas.

Em contraposição aos discursos objetificantes das línguas minorizadas, Severo (2014) defende uma política da comunicação, na qual o que importa não é a proteção da língua em si, objeto autônomo e abstrato, mas a legitimação das práticas linguísticas em que os sujeitos se inscrevem cotidianamente. Nesse sentido, a autora diz que é preciso repensar criticamente a discursivização a respeito da preservação das línguas consideradas em perigo de extinção, sob pena de, ao enfatizarmos o valor das línguas e não dos falantes, reificarmos uma concepção de língua como objeto abstrato e autônomo da vida e das pessoas. Além disso, questiona-se até que ponto esse discurso de preservação das línguas pode contribuir para uma transformação real da vida das pessoas. Em outras palavras, de que modo a preservação de uma língua minoritária pode garantir que seus falantes ascendam socialmente? Ou ainda: seria a preservação da língua um desejo dos sujeitos falantes ou dos linguistas interessados na descrição de sistemas gramaticais?

\subsection{A ineficácia dos direitos linguísticos como instrumento de mudança social}

O segundo ponto crítico que trazemos para discussão diz respeito ao papel dos direitos linguísticos na transformação social das comunidades envolvidas. Os críticos afirmam que os direitos linguísticos em defesa das línguas minoritárias, ou as políticas de planificação linguística que deles resultam, representam, em geral, instrumentos ineficazes para a transformação social dos falantes de línguas minorizadas, sobretudo indígenas e imigrantes em situação socioeconômica desfavorável. Principal representante dessa crítica, Edwards (2006, p. 104) considera que o discurso em defesa das línguas constitui um idealismo romântico: "minha crítica central é que a manutenção/revitalização linguística é sempre um trabalho difícil, que os esforços passados têm, com frequência, afundado na massa de entusiasmos românticos, porém irrealistas". Como lembra o autor, 
a mudança, mais do que a estagnação, é a norma. Os ambientes são alterados, as pessoas se movimentam, e as demandas e necessidades mudam: tais fatores têm uma grande influência sobre as línguas. $O$ desejo pela modernização e por mobilidade são, com algumas poucas exceções, um fenômeno global (EDWARDS, 2006, p. 104).

De acordo com tal perspectiva, as políticas de planificação linguística são insuficientes para frear as forças da modernização e urbanização que, em geral, levam as línguas minoritárias ao desaparecimento. Para Edwards, embora a normatização dessas línguas e sua adaptação à realidade atual sejam teoricamente possíveis (muitas línguas minoritárias já passaram por processo de normatização, incluindo a criação de um sistema de escrita, com dicionários, gramáticas etc.), isso não as torna praticáveis ou mesmo necessárias. Isto é, não é porque a língua minoritária alcança uma política de corpus e status que, automaticamente, ela alcançará valor e uso real dentro de dada comunidade (entendendo que uma comunidade pode abranger tanto um povoado como um município, um estado ou mesmo um país inteiro). Segundo o autor, a ineficácia de tais políticas linguística se deve ao simples fato de que a normatização de uma língua não muda a balança social que separa os grupos dominantes dos grupos social e economicamente mais fracos (EDWARDS, 2006). Não há como ignorar que o capitalismo, enquanto fenômeno global, pressiona grupos como os indígenas e imigrantes a mudarem, a se adaptarem à lógica do mercado e das relações de poder nele implicadas. Desse modo, Edwards nota que

o declínio e a mudança linguística são geralmente sintomas do contato entre grupos de poder político e econômico desiguais; eles são efeitos de uma causa maior, e acontece que os esforços de detê-los são sempre muito difíceis. Não se cura sarampo tampando as feridas; não se mantém uma língua lidando somente com a língua. Uma abordagem lógica para manutenção e revitalização, para deter o declínio e a mudança, é desfazer a fábrica social que tem evoluído e então reconstruí-la em um novo padrão. Isto é, novamente, teoricamente possível (considere levantes revolucionários), mas é significante aqui que muitos dos que são preocupados com a manutenção ou revitalização linguística geralmente querem apenas alguma reformulação da evolução social, não uma revolução completa (EDWARDS, 2006, p. 104, grifos do autor, tradução nossa) ${ }^{7}$.

\footnotetext{
7 “language decline and shift are generally symptoms of contact between groups of unequal political and economic power; they are effects of a larger cause, and it follows that attempts
} 
Consideramos essa passagem do texto de Edwards de extrema relevância para pensar o papel dos direitos linguísticos na transformação social. Afinal, até que ponto mudar o status de uma língua se reflete na mudança de status social de um grupo? Ao lutar pelos direitos linguísticos estaríamos, consequentemente, lutando pelos direitos políticos, sociais e civis dos seus falantes? Seria o caso de invertermos a lógica da estratégia: primeiro mudamse as relações de desigualdade social, as formas de exploração do homem pelo homem, e, como consequência, mudam-se as relações de desigualdade entre as línguas e variedades? Essa é a estratégia defendida por Edwards. De que adianta defender a equidade linguística se constitui apenas um sintoma de uma relação de iniquidade muito maior? Seria preciso primeiro combater o sistema mais amplo para que, naturalmente, chegássemos a tal equidade entre as línguas. Portanto, segundo o autor, enquanto as condições materiais forem desfavoráveis aos grupos linguísticos minoritários, não faz sentido reivindicar o uso de uma língua que não lhes propiciará a emancipação social e política que necessitam ou desejam. Essa posição também é defendida por Brutt-Gliffer (2002 apud MAY, 2005, p. 328), para quem os indivíduos podem fazer suas escolhas baseados em critérios de classe social em vez de critérios de identificação étnica. Assim, nas palavras da autora:

se você faz etnicidade, nacionalidade, ou status minoritário a unidade de análise, você pode concluir que as pessoas iriam querer ou ter interesse em manter suas línguas maternas. Se, ao contrário, você toma classe como unidade de análise, o interesse delas pode ditar uma ênfase no acesso à "língua dominante" (BRUTT-GLIFFER, 2002, p. 225 apud MAY, 2005, p. 328, tradução nossa) $)^{8}$.

to arrest them are usually very difficult. One does not cure measles by covering up the spots; one cannot maintain a language by dealing with language alone. A logical approach to maintenance and revival, to the halting of decline and shift, is to unpick the social fabric that has evolved and then reweave it in a new pattern. This is, again, theoretically possible (consider revolutionary upheavals), but it is significant here that most who are concerned with language maintenance or revitalization usually want only some reworking of social evolution, not wholesale revolution".

8 “if you make ethnicity, nationality, or minority status the unit of analysis, you can conclude that people would want to or have in their interest to maintain their mother tongue. If, on the contrary, you take class as the unit of analysis, their interest might dictate emphasis on access to 'dominant languages"'. 
Assim, a autora sugere que devemos considerar os fatores econômicos e sociais em jogo no momento em que os falantes exercem politicamente suas escolhas linguísticas.

$\mathrm{Na}$ perspectiva apresentada até o momento, a defesa dos direitos linguísticos deve, primeiramente, considerar que as escolhas feitas pelos falantes - em geral, pelo abandono da língua minoritária e sua substituição pela língua dominante -, são escolhas conscientes e racionais (EDWARDS, 2006). Os indivíduos podem, inclusive, optar por utilizar a língua majoritária como estratégia de negociação social e luta política. Dessa forma, a língua se torna um instrumento de resistência desses grupos diante de pressões políticas e econômicas. Ao mesmo tempo, outras sociedades podem reivindicar o uso de suas línguas maternas nas instituições públicas. Veja, por exemplo, o que diz um ofício encaminhado por estudantes de pós-graduação da etnia Tukano ao reitor da Universidade Federal do Amazonas:

viemos solicitar dessa pró-reitoria a garantia dos nossos direitos, como membros de uma sociedade indígena, de elaborar nossas dissertações acadêmicas, para conclusão do Mestrado, na língua materna - e, se for de interesse do Programa ou da Universidade, que seja feita a tradução dessa produção acadêmica para a Língua Portuguesa. Uma vez que não somos apenas individuos, mas pessoas coletivas que ocupam um lugar na estrutura social do sistema de descendência Tukano, tal iniciativa garante também a nossos grupos étnicos o direito de ler essa produção sobre nosso conhecimento em sua própria língua (FARIAS, 2016, grifo nosso).

Portanto, devemos questionar os parâmetros nos quais nos baseamos para afirmar o que constitui e o que não constitui objeto de interesse coletivo ou mesmo individual. Como afirmar que é a ascensão social e econômica que está em jogo para essas pessoas? Como saber o que a língua representa para os grupos étnicos? Sob o risco de cairmos em um reducionismo instrumental ou nos determinismos e essencialismos de costume, para dizer o mínimo, é importante que repensemos quais vozes estão sendo ouvidas nessa discussão. Afinal, temos legitimidade política para assumir esse lugar de fala, para definir o que é bom e o que não é para grupos falantes de línguas minoritárias?

\subsection{Afinal, língua importa?}

A terceira e última crítica que destacamos diz respeito à própria noção de língua pressuposta pelo paradigma dos direitos linguísticos . Em seu impactante livro sobre a invenção das línguas, Makoni e Pennycook 
(2007, p. 1) iniciam o texto afirmando que "as línguas foram, em seu sentido mais literal, inventadas, particularmente como parte dos projetos cristão/colonial e nacionalista em diferentes partes do mundo”. $\mathrm{Na}$ visão de Makoni e Pennycook, além de muitos outros autores que se inscrevem em uma perspectiva crítica da Linguística Aplicada (BLOMMAERT, 2005; MOITA LOPES, 2013; SEVERO, 2014; WEE, 2011), a ideia de que as línguas possam ser separadas e identificadas como "caixas" representa um construto do positivismo moderno e da ideologia nacionalista e colonialista europeia, ambas reforçadas pelos processos de padronização e letramento que marcaram a consolidação dos Estados nacionais. Nesse sentido, Makoni (2012, p. 2), ao fazer uma análise crítica do discurso dos direitos linguísticos, salienta que o processo de globalização, com seu impacto nos movimentos migratórios e na intensificação da diversidade, "impõe sérios desafios para os direitos linguísticos”, já que noções centrais como língua, comunidade e identidade são tomadas como fenômenos naturais, entidades discretas passíveis de mensuração e categorização, o que, segundo o autor, não condiz com a realidade hibridizante desses fenômenos sociais. Em contextos póscoloniais, esse fenômeno é ainda mais evidente quando se pensa sobre os projetos de descrição, levantamento de vocabulário e gramáticas das línguas locais. Como exemplifica o autor, a descoberta e a segmentação das línguas africanas serviram muito mais como estratégia para dividir as pessoas, a fim de facilitar sua dominação, do que como um retrato da realidade sociolinguística do período.

Essa mesma posição é encontrada em autores como Moita Lopes (2013), para quem a mobilidade das pessoas no mundo globalizado, desterritorializado, onde as fronteiras se tornam cada vez mais porosas, somente tende a evidenciar o modo como as misturas entre diferentes línguas, entre oralidade e escrita, entre "variedades" de uma dada língua não constituem exceções, mas parte das regras que regulamentam as práticas linguísticas. $\mathrm{O}$ autor defende que é preciso levar em conta os processos de apropriação, as heterogeneidades e misturas nas quais as pessoas se envolvem para produzir sentido. Desse modo, fica cada vez mais difícil sustentar o ideal de língua pura, sempre associado a uma nação, um povo. As padronizações e essencializações, processos dos quais nossa ideia de língua deriva, sempre estiveram a favor de um projeto de sociedade unificada e homogênea.

Portanto, na medida em que as línguas passam a ser entendidas como invenções políticas e disciplinares, autores como Makoni e Pennycook 
(2007) nos alertam sobre a necessidade de desinventar o conceito de língua e reconstituí-lo em outros termos. Tendo isso em vista, os autores ainda refletem a respeito das consequências das abordagens em defesa dos direitos linguísticos e da preservação das línguas:

as abordagens atuais da diversidade, o multilinguismo e assim por diante, muitas vezes começam com a estratégia enumerativa de contagem de línguas e romantizando uma pluralidade com base nessas supostas contagens de linguagem. A nossa afirmação é que, ao mesmo tempo em que se abrem questões de diversidade com uma mão, essas estratégias reproduzem também os tropos de invenção colonial, ignorando a história contestada das invenções linguísticas e ignorando os "danos colaterais" [...] Suas noções embutidas de linguagem podem estar perpetrando. Ao tornar a diversidade uma questão quantitativa da enumeração da linguagem, essas abordagens continuam a empregar as estratégias de censura do colonialismo, enquanto faltam à questão qualitativa de onde a diversidade reside (MAKONI; PENNYCOOK, 2007, p. 16, tradução nossa) 9 .

É nesse sentido que Makoni (2012) questiona os processos de decisão e a própria operacionalização dos direitos linguísticos. Conforme nota o autor, a sociolinguística urbana tem mostrado ser o plurilinguismo a norma e que os conjuntos linguísticos estão em constante fluxo, impedindo, portanto, limitações e categorizações - veja os casos de hibridizações nas línguas crioulas, nos pidgns e no codeswitching. Diante disso, como operar a defesa de uma língua? Onde estão os limites dessa língua ou quem delimita suas fronteiras? Qual variedade eleger? Assim, uma das controvérsias na defesa dos direitos linguísticos diz respeito a qual variedade escolher para ser considerada "a língua" a ser padronizada. Wee (2011), em seu estudo sobre a variedade do inglês falada em Singapura (o Singlish), discute a maneira como a variação intralinguística também pode ser alvo de discriminação. A eleição

\footnotetext{
9 “current approaches to diversity, multilingualism and so forth, all too often start with the enumerative strategy of counting languages and romanticizing a plurality based on these putative language counts. It is our contention that, while opening up questions of diversity with one hand, at the same time such strategies are also reproducing the tropes of colonial invention, overlooking the contested history of language inventions, and ignoring the 'collateral damage' [...] that their embedded notions of language may be perpetrating. By rendering diversity a quantitative question of language enumeration, such approaches continue to employ the census strategies of colonialism while missing the qualitative question of where diversity lies".
} 
de uma variedade para padronização pode produzir discriminações contra falantes que dominam outras variedades, não eleitas como "a língua minoritária". Segundo o autor, o resultado disso é a produção de línguas sem direito.

Na perspectiva de Wee (2011), ao lidar com a noção de direitos linguísticos é preciso questionar se e como esses direitos são assinados pela comunidade na ausência de um consenso entre seus membros em relação à desejabilidade e legitimidade. Além disso, Makoni (2012, p. 7) alerta que "em seus esforços por advogar os Direitos Humanos e os direitos linguísticos das minorias, os ativistas dos Direitos Humanos podem enquadrar e calcificar identidades que eram previamente variáveis". Assim, o autor ressalta que indivíduos e grupos experienciam a lingua de maneiras diferentes. Tendo isso em conta, somos levados, mais uma vez, a questionar: até que ponto, nós, linguistas, defensores ou críticos dos direitos linguísticos, temos legitimidade para afirmar o que uma língua significa para um indivíduo ou grupo? Do mesmo modo, se as pessoas experienciam suas práticas linguísticas de maneiras diferentes, como podemos afirmar que a defesa da língua é algo necessário ou não?

\section{Corpos pretos, línguas quebradas: protagonismo e violência epistêmica no debate sobre direitos linguísticos}

Em seu seminal trabalho Pode o subalterno falar?, a pensadora indiana Gayatri C. Spivak (2014), uma das principais referências nos estudos pós-coloniais e feministas de vertente marxista da atualidade, questiona as possibilidades que o sujeito subalterno tem de agenciar suas lutas de maneira autônoma. Para desenvolver seu argumento, a autora faz uma crítica radical à intelectualidade ocidental, que, a partir de uma concepção monolítica e essencializada de sujeito, pretende falar pelo subalterno. Apesar dos esforços atuais do Ocidente para problematizar o sujeito soberano, seu discurso proporciona "apenas uma camuflagem" para o sujeito moderno centralizado e indivisível (SPIVAK, 2014, p. 25). Nesse sentido, ao tentar construir um discurso de resistência em nome do outro e, portanto, falar por ele, "a produção intelectual ocidental é, de muitas maneiras, cúmplice dos interesses econômicos internacionais do Ocidente" (SPIVAK, 2014, p. 24). $\mathrm{Na}$ análise tecida por Spivak, não existe nenhum ato de resistência em nome do subalterno que não seja atravessado pelo discurso hegemônico. Portanto, ao tentar falar pelo outro, o intelectual acaba obliterando a voz do subalterno e reproduzindo estruturas de poder e opressão. 
Para desenvolver seu argumento, Spivak retoma o conceito de representação cunhado por Karl Marx no Dezoito Brumario de Luis Bonaparte, e lembra que existe uma confusão no entendimento do termo, pois em alemão há dois conceitos distintos para ele - enquanto Vertretung está relacionado à ideia de representação política e mediação por meio de um porta-voz, tal como as minorias são representadas diante do Estado, Darstellung refere-se à representação no sentido artístico e teatral. Aqui, o conceito de protagonismo é importante porque nos ajuda a entender a ideia de representação em seu sentido político de mediação. Se associarmos a ideia de protagonismo com Vertretung, podemos inferir que o protagonista é aquele que assume o lugar de representante, de porta-voz dos demais, aquele que fala pelo outro. Desse modo, quando o intelectual pretende falar pelo subalterno e, portanto, representálo, pretende assumir o papel de protagonista. Com isso, ele ocupa o locus enunciativo das lutas, isto é, o lugar ou espaço público e hegemônico de onde os discursos serão produzidos e ouvidos.

Além disso, se o protagonista é aquele que fala a partir de um lugar privilegiado, então o protagonismo só pode ser exercido por aqueles que têm acesso aos espaços públicos e hegemônicos. Na medida em que a condição de opressão nega ao subalterno o acesso a esses espaços, o intelectual assume, então, o papel de mediador e representante legítimo desse sujeito. No entanto, Spivak alerta para as armadilhas dessa mediação, pois, segundo a autora, ao tentar representar o subalterno, o intelectual estaria representando um sujeito essencializado, um "ser objeto" que não existe. Segundo a autora, ao "tentar reinserir o sujeito individual por meio de conceitos totalizadores de poder e de desejo", buscando representá-lo, "os intelectuais acabam representando a si mesmos" (SPIVAK, 2014, p. 54). Desse modo, por trás dessa pretensa representação e de um verniz libertário esconde-se uma agenda essencialista que desconsidera a dimensão ideológica e as contradições constitutivas de sujeitos oprimidos pelo sistema capitalista.

Mas em que medida essas considerações nos ajudam a pensar o protagonismo no debate sobre direitos linguísticos? Nas duas primeiras partes deste artigo foram apresentadas concepções de intelectuais teóricos da linguagem que, ao defenderem $\mathrm{X}$ ou $\mathrm{Y}$ teoria, apontam o que consideram legítimo ou ilegítimo na defesa dos direitos linguísticos. No entanto, nesse debate não é o subalterno que diz o que compreende como língua, comunidade linguística, identidade etc. Também não é ele quem diz se é necessário ou dispensável criar políticas de documentação e oficialização. 
Como bem observa Makoni e Pennycook (2007), são os especialistas em matéria de língua que, desde os projetos coloniais e nacionalistas, assumem a tarefa de falar pelos subalternos. Assim, embora o foco da discussão seja outro - afinal, não se trata mais de impor a língua do império ou da nação, mas de discutir direitos linguísticos -, o lugar de onde emanam os debates que vão influenciar as decisões político-linguísticas continua o mesmo. Com isso, por mais que os intelectuais mantenham uma agenda emancipatória, e tanto as propostas em defesa dos direitos linguísticos quanto seus críticos assumem esse compromisso, o subalterno nunca é o protagonista do debate, sempre mediado pelo linguista.

Nesse sentido, consideramos relevante trazer a discussão da antropóloga mexicana Marisa Belausteguigoitia a respeito da mediação na luta de mulheres indígenas zapatistas. Segundo a autora, no processo de negociação entre zapatistas e governo mexicano havia sempre um mediador não indígena para protagonizar o movimento. Belausteguigoitia (2001) discute uma dessas negociações, em que estavam presentes zapatistas indígenas e não indígenas, como o subcomandante Marcos. Assim a autora narra a situação:

Descarados e deslinguadas, indígenas presentes em corpo e língua, não haviam podido ser ouvidos e vistos ao mesmo tempo e no mesmo cenário. A atenção e escuta das demandas indígenas implicam a separação de seu corpo e de sua língua. Fazia falta que separassem seus corpos índios e suas línguas que falam um espanhol quebrado. Não se pode, além de ver o índio, e constatar sua abismal diferença, ouvi-lo. Tal evento excede todas as possibilidades modernas de compreensão, expressão e recepção de uma mensagem. É por isso que a língua e o corpo de Marcos foram receptáculos e mediações de fundamental importância para a representação e circulação das demandas indígenas. Marcos re-presenta, rearticula, media as demandas indígenas, removendo-as do "mal-lugar" em que nascem: a língua e o corpo indígenas [...] $\mathrm{O}$ índio, este mundo liminar estranho e misterioso, é idealmente representado em quantidades e doses aceitáveis para os paladares, códigos e linguagens "apropriados" de nossas classes médias (BELAUSTEGUIGOITIA, 2001, p. 234, tradução nossa) ${ }^{10}$.

\footnotetext{
10 “descarados e deslenguadas, indígenas presentes en cuerpo y lengua, no habían podido ser oídos y vistos al mismo tiempo y en el mismo escenario. La atención y escucha de las demandas indígenas implican la separación de su cuerpo y de su lengua. Hacía falta que se separaran sus cuerpos indios de sus lenguas que hablan un español quebrado. No se puede, además de ver al indio, y constatar su abismal diferencia, oírlo. Tal evento rebasa
} 
Dessa forma, a mediação acontece porque é preciso um corpo e uma língua apropriados para representar as demandas indígenas, que desloquem o "mau-lugar" de onde elas nascem - o corpo e a voz do sujeito subalterno. Como observa Belausteguigoitia (2001, p. 235, tradução e grifo nossos),

uma mediação exitosa e um símbolo da luta contra o racismo no México se dá quando a mediação é capaz de deslocar os signos do racismo, o corpo preto e a língua quebrada a outros continentes (o "bem-dizer" no corpo correto).

Em diálogo com a posição de Spivak (2014), as reflexões de Belausteguigoitia sugerem que quando o intelectual busca protagonizar a luta dos subalternos, o que ele está tentando fazer é representar um sujeito idealizado, com "quantidades e doses aceitáveis aos paladares" da classe hegemônica. Levando tais afirmações em conta, não seria esse o nosso caso, quando, enquanto linguistas, pretendemos mediar os interesses dos sujeitos falantes de línguas minorizadas? Afinal, somos nós que utilizamos a língua considerada mais apropriada para falar e ser ouvido nos espaços hegemônicos, o "bem-dizer no corpo correto". Somos nós também que detemos os códigos e conhecimentos considerados legítimos. No entanto, quando deslocamos os signos do racismo, apropriando e adaptando as demandas dos subalternos a um discurso, um corpo e uma língua adequados, domesticamos e silenciamos esses sujeitos. Portanto, precisamos questionar se essa apropriação de discursos e de línguas constituem formas particulares daquilo que Spivak (2014) chamou de violência epistêmica. Em termos gerais, a violência epistêmica consiste no apagamento, na negação e na alteração dos significados da vida cotidiana, jurídica e simbólica de indivíduos ou grupos subalternos. Recuperando o conceito de Spivak, Belausteguigoitia (2001, p. 327, tradução nossa) observa que a violência epistêmica se relaciona com "a emenda, a edição, o apagamento e até o anulamento tanto dos sistemas de simbolização, subjetivação e representação que o outro tem de si mesmo, como das formas concretas de representação e registro, memória, de sua

todas las pobilidades modernas de comprensión, expresión y recepción de un mensaje. Es por esto que la lengua y el cuerpo de Marcos han sido receptáculos y mediaciones de fundamental importancia para la representación y circulación de las demandas indígenas. Marcos re-presenta, rearticula, media las demandas indígenas, removiéndolas del 'mallugar' en que nacen: la lengua y el cuerpo indígenas. [...] Lo indio, este mundo liminal ajeno y misterioso, queda idealmente representado en cantidades y dosis aceptables para los paladares, códigos y lenguajes 'apropiados' de nuestras clases medias". 
experiência". Esses processos de violência epistêmica estão entrelaçados com a mediação que visa traduzir e diluir a voz do outro subalterno. Nesse sentido, Belausteguigoitia observa que

a violência epistêmica se relaciona com a pergunta feita por Edward Said "quem tem a permissão de narrar?". Quem relata, quem se apropria das ações de resistência das mulheres (às vezes com boas intenções e eficientes resultados; não todas as "apropriações" são feitas apenas pelo estado, nem unicamente para silenciar. Quem as põe em circulação, quem é o ventríloquo de suas vozes? A violência epistêmicas representa diferentes graus de "diluição" da voz da outridade que vai desde o sequestro e a anulação da voz, até a emenda, alteração e tradução da experiência do outro. Os graus de violência se relacionam com as possibilidades de que o relato, evento ou narração mediado - alterado para que possa ser ouvido - seja ou não reconbecivel para a população ou sujeito representado (BELAUSTEGUIGOITIA, 2001, p. 237-238, tradução e grifos nossos) ${ }^{11}$.

Com essas palavras, não seria arriscado afirmar que somos nós, linguistas, que narramos e nos apropriamos dos discursos de resistência dos sujeitos falantes de línguas minorizadas. Do mesmo modo, somos nós que colocamos em circulação as vozes e os interesses desses sujeitos, debatendo temas de direitos e políticas linguísticas em espaços legitimados. Contudo, precisamos considerar de que maneira a voz desse outro está sendo representada. Assim, quando partimos do pressuposto de que língua possui um mesmo significado para todos os sujeitos subalternos, desconsiderando a heterogeneidade de significações que ela pode assumir, ignorando a maneira como os sujeitos vivenciam e experienciam as práticas linguísticas, não estaríamos produzindo uma forma de violência epistêmica? Quando discutimos, entre nós, o que conta ou não como língua ou que língua deve ou não ter políticas afirmativas, sem, em nenhum momento, trazer a voz daqueles que serão os mais afetados por tais decisões, os sujeitos falantes

\footnotetext{
11 “la violencia epistémica se relaciona con la pregunta hecha por Edward Said ‘quién tiene permiso de narrar?’. ¿Quién relata, quién se apropia de las acciones de resistencia de las mujeres (a veces con buenas intenciones y eficientes resultados; no todas las 'apropiaciones' son hechas sólo por el estado, ni únicamente para silenciar). ¿Quién las pone em circulación, quién es ventrílocuo de sus voces? La violencia epistémica representa diferentes grados de 'dilución' de la voz de la otredad que van desde el secuestro y la anulación de la voz, hasta la enmienda, alteración y traducción de la experiencia del 'otro'. Los grados de violencia se relacionan con las posibilidades de que el relato, evento o narración mediado - alterado para que pueda ser oído - sea o no reconocible para la población o sujeto representado”.
} 
das línguas minorizadas, não estaríamos silenciando esses sujeitos? Nossos debates sobre língua são reconhecíveis para os sujeitos representados? Ao tentar representar os interesses desses sujeitos, não estaríamos cometendo o erro prenunciado por Spivak (2014) de tornar a luta do subalterno um mero objeto de interesse teórico? Afinal, para quê ou para quem importa se as línguas são espécies em extinção ou construções ideológicas? Certamente, importa a nós, linguistas, que, preocupados ou em reificar ou em desconstruir conceitos de língua, continuamos ignorando como os indivíduos ou grupos significam suas práticas linguísticas. No entanto, para os falantes das línguas minorizadas, possivelmente nenhum dos conceitos apresentados neste artigo importe. Afinal, os próprios sujeitos constroem diferentes concepções de língua, as quais são agenciadas cotidianamente em microcontextos de negociações políticas e identitárias.

O protagonismo que temos assumido nos debates sobre direitos linguísticos é algo que merece uma revisão radical de nossa parte. É claro que os defensores dos direitos linguísticos têm cumprido um papel fundamental em denunciar a ideologia da homogeneidade linguística que ainda prevalece no interior dos Estados nacionais. Do mesmo modo, a Linguística Aplicada Crítica tem produzido uma importante desconstrução teórica de conceitos como língua e identidade. Contudo, precisamos ainda refletir sobre a maneira como essa representação ocorre e o lugar que pretendemos ocupar nessa discussão. Para isso, temos que assumir que somos intelectuais teóricos da linguagem vinculados a instituições/universidades ocidentais cujos interesses são marcadamente hegemônicos. Portanto, falamos de um lugar privilegiado, o lugar do discurso considerado científico, e nossas falas proclamam posicionamentos epistemológicos que são atravessados por discursos hegemônicos. Além disso, temos corpos e línguas (inglês, francês, espanhol, português...) considerados legítimos, corretos e apropriados para os espaços hegemônicos. Nossa fala terá, portanto, mais oportunidade de ser ouvida e nossa opinião, de ser mais legitimada do que, por exemplo, a fala do sujeito indígena, cujo corpo e cuja língua são vistos como incorretos, para usar a expressão de Belausteguigoitia (2001).

Nesse ponto, cabe retomar a questão central do texto de Spivak (2014): pode o subalterno falar? A resposta que Spivak nos oferece é negativa, o subalterno não pode falar, pois na condição de oprimido pelo capital socializado, esse sujeito não tem acesso a espaços hegemônicos 
que lhe permitam falar e ser ouvido ${ }^{12}$. Mas se o intelectual não pode falar pelo subalterno, sob o risco de silenciá-lo, e o subalterno não pode, ele próprio, falar, que saída temos, então? A saída, aponta Spivak (2014), é o uso estratégico das ferramentas hegemônicas. Segundo a autora, o intelectual pós-colonial precisa "aprender a criticar o discurso pós-colonial com as melhores ferramentas que ele pode proporcionar e não apenas substituindo a figura perdida do(a) colonizado(a)" (SPIVAK, 2014, p. 114). Assim, não se pode falar pelo subalterno, mas se pode lutar contra as subalternidades.

Nesse sentido, em vez de assumirmos uma postura de porta-vozes do interesse dos sujeitos falantes das línguas minorizadas, nossa tarefa é a de criar condições dentro dos espaços institucionais aos quais estamos vinculados para que esses sujeitos possam ter voz e ser ouvidos. Como isso pode ser feito? Para responder a essa pergunta, consideramos relevante trazer a contribuição de Blommaert (2005), Canagarajah (2005) e Hornberger e Johnson (2007), os quais têm sugerido a realização de pesquisas etnográficas que identifiquem o modo como os sujeitos negociam as práticas linguísticas em contextos locais. Uma agenda etnográfica, defendem esses autores, é fundamental para dar visibilidade ao modo como os sujeitos não só interpretam categorias como língua e identidade, mas também as agenciam politicamente. Para Blommaert (2005, p. 403), se quisermos construir um direito linguístico que não seja cúmplice do discurso hegemônico, devemos começar a entender "o que as pessoas realmente fazem com a linguagem, $\mathrm{O}$ que a linguagem faz com elas, o que a linguagem significa para elas, e em que modos específicos a linguagem importa para elas". De modo semelhante, Canagarajah (2005) afirma ser urgente que nossas pesquisas contribuam não só com a investigação mas, sobretudo, com a legitimação das políticas linguísticas bottom-up, isto é, com as políticas realizadas de baixo para cima. $\mathrm{Na}$ literatura, a política linguística bottom-up refere-se às ações políticolinguísticas que são engendradas e protagonizadas pelos próprios sujeitos falantes, enquanto as políticas top-down são aquelas determinadas de cima

\footnotetext{
${ }^{12}$ Embora o uso do termo falar seja figurativo para o argumento de Spivak, devemos ressaltar que, no caso dos sujeitos falantes de línguas minorizadas, tal metáfora ganha um sentido quase literal - o falante de quechua que não sabe o espanhol, por exemplo, não pode falar, tanto porque não vai ser ouvido, como também porque não vai ser entendido. Sem o conhecimento da língua hegemônica, o diálogo se torna ainda mais difícil. Nesse caso, o sujeito subalterno é silenciado duas vezes, já que mesmo quando tenta falar, não há meios para se fazer ouvir.
} 
para baixo, ou seja, por aqueles que estão de fora, mas acima na hierarquia social de poder, como o Estado (HORNBERGER; JOHNSON, 2007). Portanto, a investigação etnográfica de políticas linguísticas bottom-up é considerada uma estratégia por meio da qual o teórico da linguagem pode construir um espaço onde a voz do subalterno seja ouvida. Ao publicar um trabalho dessa natureza, no lugar de debater conceitos pré-concebidos e sugerir soluções, o intelectual cumpre o papel de garantir que a voz e as vivências do sujeito falante de língua minoritária se façam presentes em um espaço legitimado como o é a academia.

\section{Considerações finais}

Se há algo que os movimentos sociais, étnicos, feministas, negros e LGBT têm nos ensinado é a importância do protagonismo do oprimido nas lutas. $\mathrm{O}$ sujeito familiarizado com qualquer um desses movimentos sabe que, na militância, o protagonista não pode ser, jamais, aquele que fala de um lugar privilegiado, mas sim aquele que vivencia a opressão cotidianamente. $\mathrm{Na}$ tentativa de representar os interesses desses grupos, o intelectual militante acaba, muitas vezes, silenciando esses sujeitos e, com isso, aprofundando as relações de opressão. Nesse sentido, o debate sobre os direitos linguísticos merece uma revisão radical. Enquanto linguistas engajados nesse tema, nossa tarefa não pode mais ser a de cumprir o papel de mediadores dos sujeitos falantes de línguas minorizadas, ainda que nossos corpos e nossas línguas sejam aqueles aceitos nos espaços hegemônicos.

Spivak (2014, p. 27) é clara quando diz que nós, investigadores ocidentais, precisamos assumir o nosso "próprio envolvimento na história intelectual e econômica", sob o risco de sermos cúmplices de projetos hegemônicos. Portanto, nossa tarefa não é falar pelo subalterno, discutindo entre nós o que deve ou não ser objeto de planificação linguística, mas criar condições e espaços que permitam a esses sujeitos dizerem que políticas linguísticas eles esperam do Estado. Para isso, ressaltamos a importância de pesquisas etnográficas que ponham em evidência as vivências e práticas linguísticas desses indivíduos e grupos, assim como políticas linguísticas feitas de baixo para cima. Se mantivermos a prática de ignorar as significações e as subjetividades desses sujeitos, continuaremos reproduzindo as violências epistêmicas tão próprias dos projetos hegemônicos colonialistas e nacionalistas.

Os movimentos por direitos linguísticos que estão sendo engendrados pelas comunidades indígenas, de descendentes imigrantes e surda no 
Brasil constituem casos de mobilização política protagonizada pelos próprios sujeitos que, historicamente, têm sido silenciados em razão de suas línguas (cf. MORELLO, 2015; SILVA, 2016a). Tais iniciativas merecem maior atenção. Portanto,como nós, acadêmicos, podemos contribuir para fortalecer esse tipo de movimento ou outros que queiram seguir caminhos diferentes? Acreditamos que a saída passe pela realização de pesquisas etnográficas que priorizem o olhar dos subalternos sobre as práticas linguísticas, convidando representantes de comunidades ou indivíduos para darem palestras nas universidades sobre suas práticas de luta e vivências como falantes de línguas minoritárias, bem como formulando projetos de extensão que permitam parcerias entre a universidade e comunidades linguísticas, entre outras possibilidades.

\section{Agradecimentos}

Agradeço ao Conselho Nacional de Desenvolvimento Científico e Tecnológico (CNPq) pela concessão da bolsa e financiamento desta pesquisa.

\section{Referências}

ANDERSON, B. Comunidades Imaginadas: reflexões sobre a origem e difusão do nacionalismo. 4. ed. São Paulo: Companhia das Letras, 2015.

BELAUSTEGUIGOITIA, M. Descarados y deslenguadas: el cuerpo y la lengua india en los umbrales de la nación. Debate Feminista, México, v. 12, n. 24, p. 230-254, 2001.

BESSA FREIRE, J. R. Da "fala boa” ao português na Amazônia brasileira. Revista Ameríndia, Sorbonne, n. 8, p. 39-83, 1983.

BLOMMAERT, J. Situating language rights: English and Swahili in Tanzania revisited. Journal of Sociolinguistics, Oxford, v. 9, n. 3, p. 390-417, 2005. DOI: https:/ / doi.org/10.1111/j.1360-6441.2005.00298.x

CANAGARAJAH, A. S. Reclaiming the local in language policy and practice. Mahwah: Lawrence Erlbaum, 2005.

EDWARDS, J. Language revitalization and its discontents: an essay and review of Saving Languages: an introduction to language revitalization. In: GRENOBLE, L.; WHALEY, L. (Ed.). Saving Languages: an introduction to language revitalization. Cambridge: Cambridge University Press, 2006. p. 101-120.

FARIAS, E. Educação: alunos Tukano escrevem dissertação de mestrado da Ufam na língua da etnia. Amazônia real. 26 fev. 2016. Disponível em: <http://bit. ly/2vjmIIf>. Acesso em: 31 dez. 2016. 
FISHMAN, J. Reversing language shift. Clevedon: Multilingual Matters, 1991.

HAMEL, R. E. Derechos lingüísticos como derechos humanos: debates y perspectivas. Alteridades, México, v. 5, n. 10, p. 11-23, 1995.

HORNBERGER, N.; JOHNSON, D. C. Slicing the Onion Ethnographically: Layers and Spaces in Multilingual Language Education Policy and Practice. Tesol Quarterly, Alexandria, v. 41, n. 3, p. 509-532, 2007. DOI: https://doi. org/10.1002/j.1545-7249.2007.tb00083.x

HOBSBAWN, E. Naçôes e nacionalismo desde 1780: programa, mito e realidade. 6. ed. São Paulo: Paz e Terra, 2013.

JACQUEMET, M. Transidiomatic practices: Language and power in the age of globalization. Language and Communication, San Francisco, v. 25, n. 3, p. 257-277, 2005. DOI: https://doi.org/10.1016/j.langcom.2005.05.001

KRAUSS, M. The world's languages in crisis. Language, Alaska, v. 68, p. 4-10, 1992. DOI: https://doi.org/10.1353/lan.1992.0075

MAKONI, S. Languages and human rights discourses in Africa: lessons from de African experiences. Journal of Multicultural Discourses, Abingdon, v. 7, n. 1, p. 1-20, 2012. DOI: https://doi.org/10.1080/17447143.2011.595493

MAKONI, S.; PENNYCOOK, A. Disinventing and reconstituting languages. In: MAKONI, S.; PENNYCOOK, A. (Org.). Disinventing and reconstituting languages. Bristol: Multilingual Matters, 2007. p. 1-41.

MAY, S. Language rights: moving the debate forward. Journal of Sociolinguistics, Oxford, v. 9, n. 3, p. 319-347, 2005. DOI: https://doi.org/10.1111/j.13606441.2005.00295.x

MOITA LOPES, L. P. Como e por que teorizar o português: recurso comunicativo em sociedades porosas e em tempos híbridos de globalização cultural. In: MOITA LOPES, L. P. (Org.). O português no século XXI: cenário geopolítico e sociolinguístico. São Paulo: Parábola, 2013. p. 101-119.

MORELLO, R. (Org.). Leis e línguas no Brasil: o processo de cooficialização e suas potencialidades. Florianópolis: IPOL, 2015.

NETTLE, D.; ROMAINE, S. Vanishing Voices. Oxford: Oxford University Press, 2000 .

OLIVEIRA, G. M. O que quer a linguística e o que se quer da linguística: a delicada questão da assessoria linguística no movimento indígena. Caderno Cedes, Campinas, v. 19, n. 49, p. 26-38, 1999. DOI: https://doi.org/10.1590/S010132621999000200004 
OLIVEIRA, G. M. Brasileiro fala português: monolinguismo e preconceito linguístico. In: SILVA, F. L.; MOURA, H. M. O direito à fala: a questão do preconceito linguístico. 2. ed. Florianópolis: Insular, 2002. p. 127-136.

OLIVEIRA, G. M. Declaração Universal dos Direitos Linguísticos: novas perspectivas em políticas linguísticas. Campinas: Mercado de Letras, Associação de Leitura do Brasil; Florianópolis: IPOL, 2003.

PILLER, I. Linguistic Diversity and Social Justice: An introduction to Applied Sociolinguistics. New York: Oxford University Press, 2016. DOI: https://doi. org/10.1093/acprof:oso/9780199937240.001.0001

SANTOS, B. S. (Org.). Reconhecer para libertar: os caminhos do cosmopolitismo multicultural. 2. ed. Rio de Janeiro: Civilização brasileira, 2010.

SEVERO, C. G. Línguas e Estados nacionais: problematizações históricas e implicações. In: SEVERO, C.; SITOE, B.; PEDRO, J. Estão as línguas nacionais em perigo? Lisboa: Escolar, 2014. p. 9-36.

SKUTNABB-KANGAS, T.; PHILLIPSON, R. A human rights perspective on Language Ecology. In: CREESE, A.; MARTIN, P.; HORNBERGER, N. (Ed.). Encyclopedia of Language and Education. 2. ed. New York: Springer, 2008. p. 3-14. DOI: https://doi.org/10.1007/978-0-387-30424-3_217

SPIVAK, G. C. Pode o subalterno falar? 2. ed. Belo Horizonte: UFMG, 2014.

SILVA, J. I. Do mito da língua única à política do plurilinguismo: desafios na implementação de leis de cooficialização linguística em municípios brasileiros. Revista Matraga, Rio de Janeiro, v. 23, n. 38, p. 223-241, 2016a.

. Práticas transidiomáticas e ideologias linguísticas no rap guaranikaiowá: Brô MC's: a mistura guarani-português como estratégia de negociação social e de luta política. Revista Domíniosde Lingu@gem, Uberlândia, v. 10, n. 4, p. 1424-448, 2016b.

VARENNES, F. The human rights dimension and challenges of linguistic rights. In: INTERNATIONAL CONFERENCE INTEGRATION AND EXCLUSION: LINGUISTIC RIGHTS OF NATIONAL MINORITIES IN EUROPE, 2015, Vilnius. Anais... Vilnius: SNPL, 2015. p. 39-56.

WEE, L. Languages without rights. Oxford: Oxford University Press, 2011.

Data de submissão: 31/12/2016. Data de aprovação: 17/05/2017. 